\title{
Scaffolding Discovery Learning Spaces
}

\author{
Shalin Hai-Jew \\ Instructional Designer \\ Kansas State University \\ Manhattan, KS USA \\ shalin@k-state.edu
}

\begin{abstract}
Discovery learning spaces may be created in online learning environments to encourage learner-directed training and learning. Such "autodidaxy" learning tends to be autonomous and learner-directed. This chapter addresses the importance of learner empowerment through the building of learner orientation, decision supports, community supports, and new learning archival. This also advocates promotion of learner selfefficacy and decision-making. The Web-based design of online discovery spaces needs to be aligned in pro-learning ways based on relevant theory, research and in-field applied practices.
\end{abstract}

Keywords: autodidaxy, discovery learning, independent learning, motivational interference, self-directed learning, self-regulated learning, self-efficacy

\section{Introduction}

With the growing sophistication of automation in pedagogy, rich authoring tools for multimedia and faster Internet connectivity, various opt-in learning spaces offer more effective learning opportunities for users. Once such spaces are designed and created, they may offer long-term usability, particularly if they're supported and maintained by an active, virtual learning community.

In work life, discovery learning may help people head-off skills decay. It may help hone the employability skills of many. It may help people explore different educational and vocational pathways. Discovery learning spaces may be used to offer end-user training via a fully developed site. Discovery learning spaces may be used for pre- and post- synchronous training activities to add value to the live events (whether virtual or face-to-face). They may be educational laboratories focused around particular subject matter, with guided inquiry learning (Armstrong \& Perez, Feb. 2001, p. 14). The many applications of discovery learning have not yet been fully exploited. The wide diffusion of computer technologies in work places means a broad "installed base" for the deployment of online discovery spaces. Organizations are turning to self-discovery learning because it may be cost-effective, repeatable, accessible 24/7/365, customizable to various learners, and if well designed, efficacious for learning and training.

This paper opens with a brief background into discovery learning spaces online and an exploration of discovery learning spaces. It continues to define discovery learning spaces and discovery learners. The educational theories that underpin discovery learning spaces are explored briefly. The new technologies that support discovery learning are described. Design strategies for online discovery learning spaces will address the need to build up self-learners, contextualize and sequence the learning, engage the social aspects of self-learning, capture the new discoveries, and maintain such spaces in the long-term. A future trends discussion follows.

\section{Background}

Discovery learning has come to the fore. The greater spread of informational literacy has enabled learners to approach their own learning with more sophistication. Modern literacy goes beyond text to "image and screen literacy" (Oblinger, Barone, \& Hawkins, 2001, as cited in Annetta, Murray, Laird, Bohr \& Park, 2008, p. 9). Digital literacy is seen as consisting of six skills: "photo-visual thinking, reproduction thinking, non-linear thinking, information thinking, socio-emotional thinking, and real-time thinking ", 
which relates to the ability of users to perform effectively in real-time environments which require processing simultaneously large volumes of stimuli which appear in real-time and at high-speed" (EshetAlkalai, Dec. 2007, p. 57). Self-discovery learners tend to be empowered to choose what they want to learn. They are free to schedule and pace their learning around their own commitments, with their own amorphous, informal learning plan. They often learn by trial-and-error.

This approach to learning is not without controversies. Self discovery learning involves risks to learners of inaccuracies in learning, poor decision-making, untested ideas, inaccurate conclusions or naïve mental modeling. Some argue that the phenomenon of an independent learner is a product of noncommunal individualistic societies and may not be appropriate in other social contexts (Leathwood, 2006, p. 613). Many discovery learning spaces take a presential, media-driven strategy for interactivity, where the media controls the flow of the learning experience. Only a few are user-driven in terms of directing the learner experience. With proper instructional design, scaffolded discovery learning may be more effective, supportive of unique learners, and more communal.

\section{Online Discovery Learning Spaces}

Discovery learning tends to be learner-initiated and learner-driven. Learners' self-will is a critical aspect. Such learners academically self-regulate (Mullen, 2007, p. 406). Current discovery spaces often do not usually involve expert facilitation (no oversight, no targeted interventions, and no human tutoring); many do not even involve learning community building; many do not show a clear sense of design. Such environments may be virtual learning environments (VLEs); networks or communities of practice spaces; 3D immersive and persistent metaworlds; persistent spaces built in learning / course management systems; interactive websites, or data repositories or digital libraries with computer-mediated communications and work suite functions.

Some discovery learning spaces are publicly available and fuse various technologies: learning management systems, live chat, live virtual classrooms, digital repositories, databases of digital learning objects (LOs) and knowledge management systems. The Semantic Web may be seen as a kind of discovery learning space, with its making available of learning objects through the automated capture of LO metadata (Shafrir \& Etkind, 2006). Others are closed online discovery spaces for a network or a community of practice.

Discovery learning spaces may include plenty of interactivity and learner interdependence. They may be built to include human facilitation, either as a constant aspect or an occasional one. Many of these challenges may be mitigated with proper discovery learning space design-for new learner orientation, usability, accessibility, learning sequencing and pacing, innovations, learning community building, and continuing learning - to enhance the "executive process" of learning.

\section{Who are Discovery Learners?}

Learners who tend to use the tools of discovery effectively have low dependency needs. Certainly, independent learning is common enough in the day-to-day lives of most people, but such unsupervised learners engage in self-learning regularly, and they act in a purposive and self-disciplined way. Adult learners tend to become more self-directed in their learning as they mature (Knowles, 1970, 1980, as cited in Merriam \& Caffarella, 1999, p. 289).

Such active learners demonstrate high self initiative; they may pursue learning based on lifelong learning, hobbies, personal interests and career interests. Their inquisitiveness may mean broader horizons and higher levels of innovation. Autonomic learners pursue knowledge and skills. "AL (autonomic learning) usually means active, self-conscious and independent learning, which is opposite to the type of passive, mechanical or receptive learning" (Wang \& Li, 2007, p. 259).

Such internally driven learners must play an executive role in their own learning, involving efforts: "to guide and control their own learning, to set learning goals, to select different learning methods and learning activities according to different learning tasks, to supervise the learning process, to evaluate the results of learning, and even to ask for help" (Wang \& Li, 2007, p. 259). "Investigative learning" tasks may involve long-term, complex learning activities (Davydov, 1988, as cited in Stary \& Totter, n.d., p. 41). 


\section{Theoretical Underpinnings}

A mix of educational theories informs the development of online discovery learning spaces. These involve adult learning theories; multiple intelligences (Gardner, 1983); experiential learning and learning styles (Kolb, 1984), cognitive load theory (Sweller, 1988), and constructivism (Piaget). The communities of practice (Rogoff, 1985; Lave \& Wenger, 1991), zones of proximal development (Vygotsky, 1978) and social cognitive theory (Bandura 1988) also inform the building of these spaces, along with findings from computer-supported collaborative learning (CSCL) and computer supported cooperative work (CSCW).

In the employment context, the learners are adults, so andragogy's focus on learner needs is critical: "developing awareness of learning needs, facilitating problem-solving skills, and marshalling resources to meet them. The learner is presumed to be largely self-directed: 'education' involves providing resources and guidance to the learner's problem-solving efforts" (Bogue, 1989, p. 448). The assumption is that such learners have busy family and work lives. Their interests in learning are practical and problem-solving based.

Unique learner learning styles require the need to design teaching with sensitivity to those preferences (Hein \& Budny, 1999) and to multiple intelligences. The success of discovery learning spaces will depend in part on the ability to customize and personalize learning based on learner needs (perceived and un-perceived). Multimedia and cognitive theories (Clark \& Mayer, 2003) influence the building of digital objects and spaces within the limits of cognitive processing. Learners need to build strong mental models for effective knowledge acquisition and transfer (Ramalingam, LaBelle, \& Wiedenbeck, 2004, p. 171).

Mayer and Moreno's (2003) cognitive theory of multimedia learning suggests that "a successful learning process includes students': (a) meaningful interaction with academic materials (Moreno, Mayer, Spires \& Lester 2001); (b) selection of relevant verbal and non-verbal information (Paivio 1986); (c) organization of information into corresponding mental models or representations (Mayer \& Moreno 2002; Moreno \& Mayer 2002); and (d) integration of new representations with existing knowledge" (Pressley, Wood, Woloshyn, Martin, King \& Menke 1992, as cited in Moreno, 2004, p. 101). Schemas are helpful for learning because they limit the demands on working memory "by allowing many elements to be treated as a single element in working memory" (Chi, Glaser \& Rees 1982, as cited in Moreno, 2004, p. 101). Larger understandings encapsulate more complex learning within.

Constructivism, particularly the social construction of knowledge, affects the work of collaborative knowledge creation. "Garrison (1991) developed an interaction analysis model for analyzing online discourse that similarly focused on assessing critical thinking, but at the same time highlighted the social process of negotiation and knowledge co-construction. This model comprised five phases: sharing I comparing, dissonance, negotiation, co-construction, testing and application, which paralleled and built on a conceptualization of critical thinking as a five-stage sequential process: problem identification, problem definition, problem exploration, problem applicability and problem integration" (Law, n.d., p. 374). Learning occurs at both the individual and group levels. Gunawardena, et al. (1997)used a patchwork quilt metaphor comprising five phases of negotiation and co-construction (sharing I comparing, dissonance, negotiation / co-construction, testing tentative constructions and application of newly constructed knowledge) to describe their understanding of the interdependence and interaction between the individual and the social construction of knowledge (Law, n.d., p. 374).

The "C4P Framework for Communities of Practice" shows the interaction of conversation, connections, context and content for a particular purpose, namely, that of building knowledge (Hoadley \& Kilner, P.G., n.d.). The research in computer-supported collaborative learning (CSCL) may have implications in terms of structuring online learning spaces: "...CSCL has often been adopted by educators who value the capacity of the learner to undertake autonomous learning and to problem solve as important outcomes to target" (Law, n.d.).

Bandura's triadic model (1986) offers a social cognitive perspective of self-regulated learning that focuses on "the dynamic, interactive, and reciprocal relationships between context, person, and behaviors." Bandura (2001) sees the learner-agent as finding "extrinsic motivation and situational opportunities" in the learning environment (Mullen, 2007, p. 407). Here, motivational mindsets are mediated by situation-specific factors to affect the actual performance (Niemivirta, 2006, p. 255). The 
social exchange theory offers insights about "the exchange of intangible social costs and benefits (such as respect, honor, friendship and caring)" (Wu, Lin \& Lin, 2006, pp. 2 - 3).

"A Normative Model for Virtual Discovery Learning Spaces" offers a process view of a self-regulated learning moving through a discovery learning space. Here, various needs are met for orientation, learning sequencing, learner decision-making; individuated learning; inter-communications and collaboration, and original discovery.

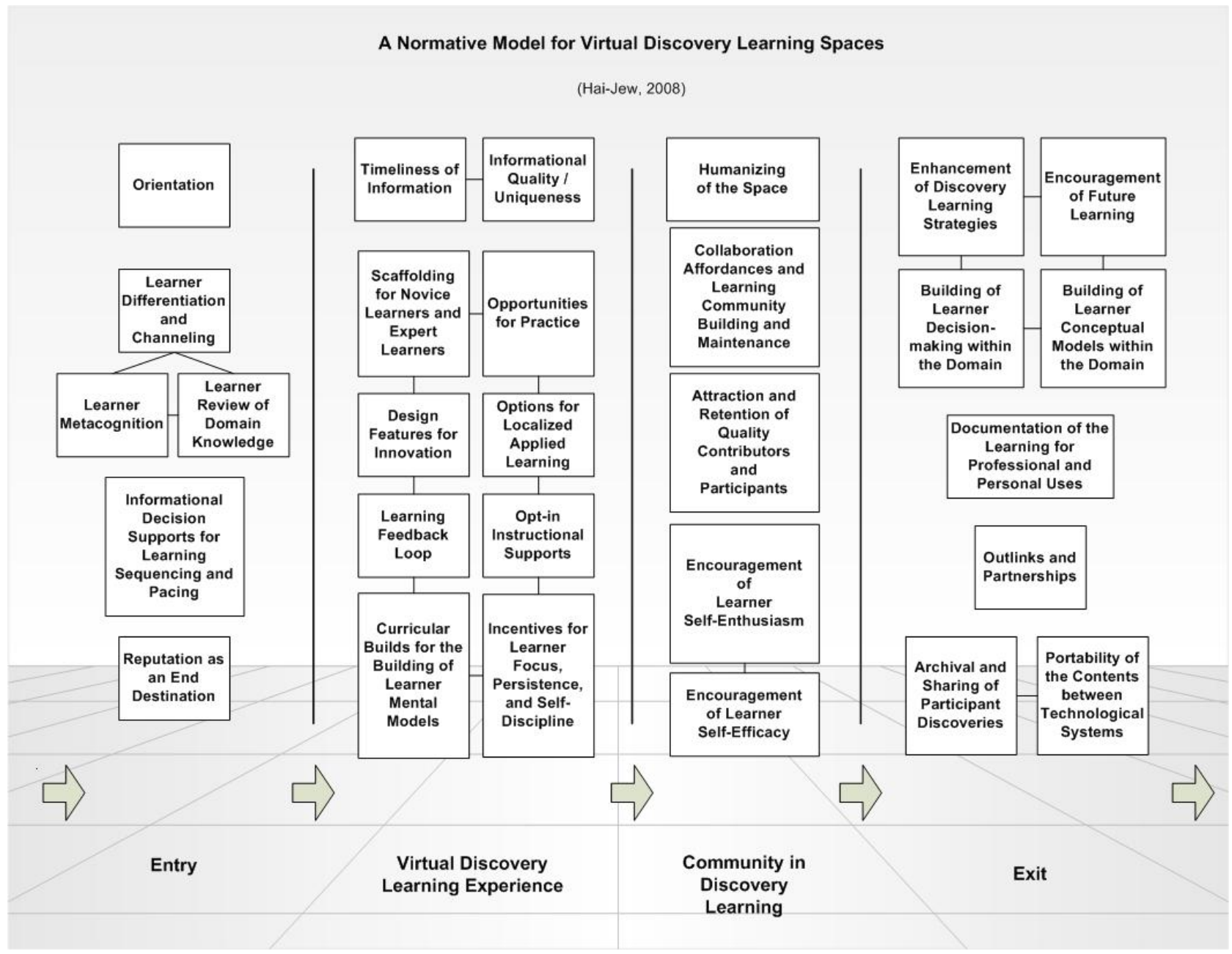

Figure 1. A Normative Model for Virtual Discovery Learning Spaces

\section{Modern Technologies for Discovery Learning}

A range of technologies and functionalities may be built into discovery learning systems. Such systems may host any range of digital learning object types: animated tutorials, screen captures, audio, video, ebooks, interactive objects, small games, and still images. Intelligent tutorial agents may humanize the space. 3D immersive objects and avatars may be set to roam in digital ecosystems. Artificial ecosystems may have the autopoetic rules for their various artificial life entities set and then left to run (McCormack, 2007 , pp. $301-307)$. Here, human learners may engage in the discovery of novelty without explicit teleological self-realization goals.

Discovery learning spaces may offer opportunities for both informal and formal learning, personal and professional, non-academic and academic. The learning may be just-in-time or part of a lifelong learning focus. These spaces offer self-paced opportunities for learning and experiential practice. With the 
advancements in educational technologies, sites may deliver educational and training games, simulations, knowledge ecologies, synchronous and asynchronous interactivity among a learning community (through group support systems, document sharing, application sharing and other collaboration technologies), immersive 3D experiences, and artificial, emergent, and autopoetic ecosystems. Various types of self-learning activities exist: reading, exploring and experiencing a digital space, problem-solving, and creating digital artifacts.

Feedback loops offer occasions for self-reflection, self evaluation and decision-making about additional learning. Much of the learning is informal and may be inductive. Some discovery learning may be more structured and formal. With the self-discovery learning skills that may be acquired through such sites, ideally, the World Wide Web (WWW) itself may be approached as a discovery learning space. "Discovery" implies not only learning something new to the self but possibly new to the knowledge domain. People who contribute new learning to a field generally have sufficient mastery. The current technological infrastructure, too, makes possible the building of an "institutional memory" in discovery learning spaces and the capability to archive new digital artifacts, with knowledge management.

Learner tracking, participant profiling, work roles, and other strategies have enabled the personalization and customization of learning based on perceived learner needs and pedagogical suitability. A discovery learning system should be responsive in unique ways. Recent developments in various authoring tools and e-learning technologies have enhanced accessibility and usability.

Various functionalities are required in the building of a discovery learning space. Wouter defines an ideal architecture for discovery learning as having the following main features: a frame of reference, collaborative tools, experimentation spaces, and collaborative scenarios (Carreras, Skarmeta, \& Graciá, 2005, n.p.). Figure 2 below addresses "Main Opt-in Functions View of Discovery Learning Spaces."

\section{Designing Online Discovery Learning Spaces}

The design of online discovery learning spaces involves a symphony of tools and pedagogical design elements. This process generally begins with the anticipated learners to that space.

Wedemeyer describes some traits of autonomous learners. They enjoy planning ahead in the short-term and the long-term and tend to persist with their plan. They use time practically. He writes, "They enjoy reading, writing, listening, and discussing. They have open minds to learning new things. They enjoy questioning, testing, and analyzing. They are not afraid of being different. They like to form generalizations, look for principles, and find the basic structural ideas in any subject. They have developed skills in note taking, remembering, and relating. They work cooperatively with others, but enjoy being 'on their own' in learning" (Moore, Dec. 1973, p. 668). This profile fits neatly into the discovery learning approach, which suggests a design that enhances learner decision-making about their own learning and then provides the relevant contents for their work. Suggestions for learner actions may be directed towards a particular objective; be purely exploratory, or be "fortuitous" (Spear, 1988, pp. 212 - 213, as cited in Merriam \& Caffarella, 1999, p. 296).

Orientation. Learners may benefit from "being explicitly taught declarative, procedural, and conditional knowledge regarding the utilization of high-level SRL (self-regulated learning) strategies such as the coordination of information sources and summarization" (Green, et al., 2006, p. 215). For learners entering a new learning space, they may experience disorientation and difficulty to proceed (Ardito, et al., 2004, p. 81). One critical aspect of a discovery learning space is to support new learners in acclimating and orientating themselves. This needs to be done with the provision of information, the physical design of the learning space, and the deployment of particular technologies. Over time, as participants shape their own interactions and discourse with others, they will be empowered "through the situated practices of participants" (Qureshi \& Fayard, 2008, p. 4). 
Main Opt-in Functions View of Discovery Learning Spaces

(Hai-Jew, 2008)

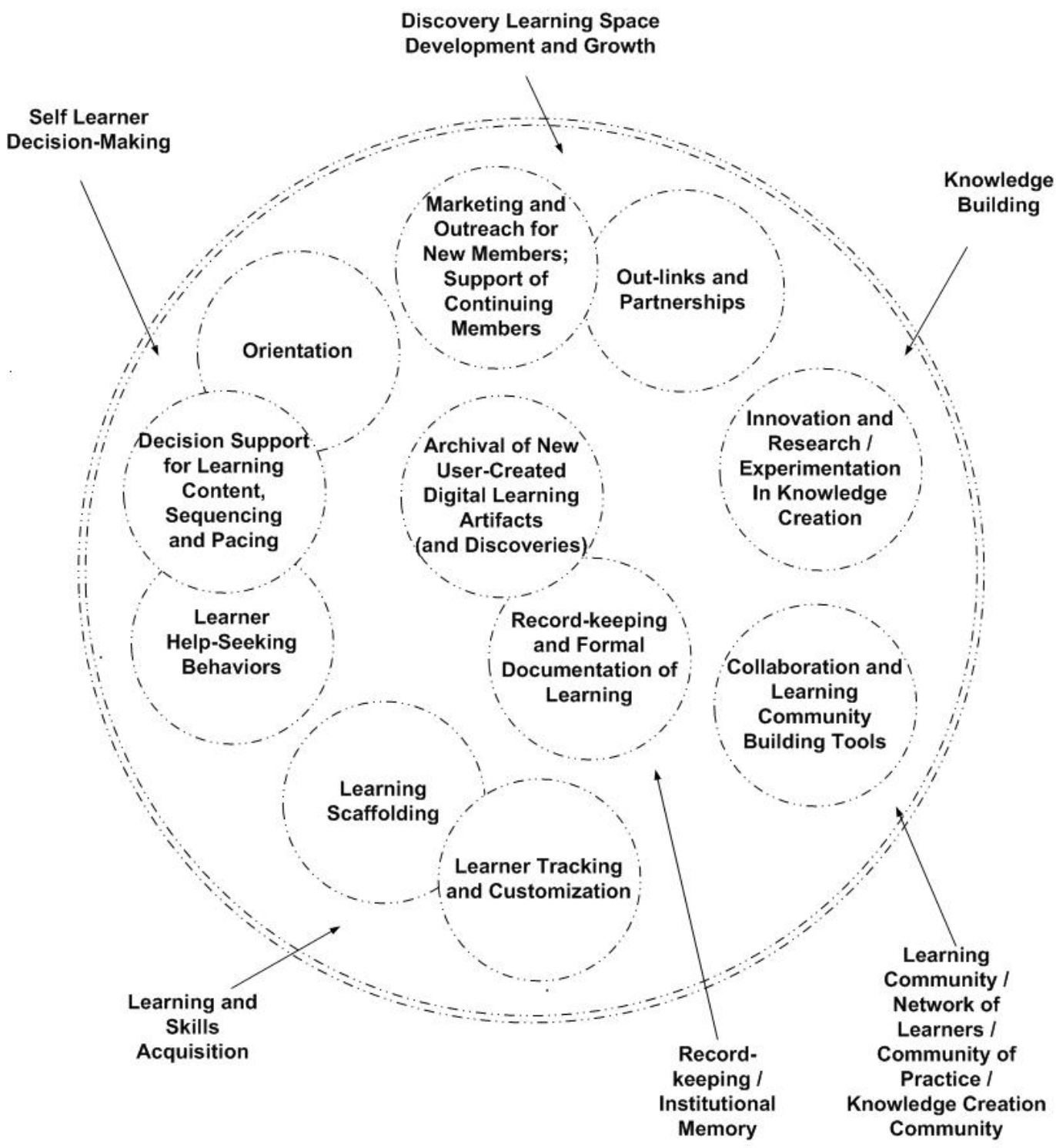

Figure 2. Main Opt-in Functions View of Discovery Learning Spaces

While a discovery learning site needs to make its tools accessible through clear organization and labeling for the easy assimilation of newcomers and the servicing of user needs, there need to be other strategies in play beyond a learner opt-in a la carte presentation. Discovery learning sites will also need tools to be able to "version" a site to meet individual learner preferences and needs.

Guided discovery. Learners need to develop an internal conceptual framework to determine what information is or is not relevant in a particular field. Guided discovery should be an opt-in feature to a discovery learning space to help learners navigate the site, make decisions, and form new learning competencies. This "weak guidance" needs to be nuanced, non-intrusive and non-directive, and preferably, it should be opted into by the users. Learner guidance may limit the degrees of learners' freedom (Zumbach, Schönemann, \& Reimann, n.d., p. 759). The idea that discovery learning spaces should have scaffolding for independent learners aligns with the shift from the information processing 
(IP) model to the self-regulated learning (SRL) one (Pintrich, 2000b; Winne \& Hadwin, 1998; Zimmerman, 2000, as cited in Pintrich, 2004, p. 386).

Tools for goal-setting and planning. The importance of goal-setting in learning has been established through plenty of research. "A large body of literature reveals the benefits of goal setting (see Lathan \& Locke, 2001). Students who exhibit SRL (self-regulated learning) begin the learning process by setting learning goals (Zimmerman \& Martinez-Pons, 1986). Linking learning goals with students' personal goals can enhance motivation (Talbot, 1997). In addition, establishing this learning orientation can promote SRL" (Talbot, 1996, as cited in Schloemer \& Brenan, Nov. - Dec. 2006, p. 82).

Learner monitoring. Discovery learning sites may use learner tracking to find the most effective learning via "swarm intelligence" trails through domain contents. Aggregate data-mining may also help in the site's updating. Others view all participants in a learning situation as having the potential to scaffold the learning for others (Pata, Sarapuu, \& Archee, n.d., n.p.). System monitoring may feed relevant information to self-learners in their self-monitoring, a key component of self-regulated learning. Students monitor their progress toward learning goals and modify their behavior to improve their learning process (Schloemer \& Brenan, Nov. - Dec. 2006, p. 82).

The need for guided feedback. Novice learners experience more potential challenges in discovery learning spaces, and yet, they are a critical constituency for virtually all fields. However, because of their lack of experience, they may end up with more of an extraneous cognitive load on their limited working memory when processing complex verbal and pictorial presentations (Moreno, 2004, pp. 101 - 102). Guided feedback lightens part of this cognitive load in "discovery-based multimedia environments when pedagogical agents guide them with explanatory feedback during the process of meaning making. Explanatory feedback reduces the extraneous cognitive load that results from having novice students search for a plausible explanation to the correctness or incorrectness of their problem solutions in discovery environments. This, in turn, frees capacity for schema acquisition, which eventually promotes learning" (Moreno, 2004, p. 102).

Contextualizing and sequencing. The context of learning may relate to a particular culture or social milieu. It may involve a meta-perspective, a framework through which to understand a subject area. With the design of atomistic stand-alone learning objects stripped of their cultural context, this often must be built back into the learning. If a real-world context is important for the applicability of the applied and practical learning, or if situated learning is required for a particular knowledge domain, those need to be built into the site. Discovery learning spaces may offer three general models linked to self-directed learning: "linear, interactive, and instructional" (Merriam \& Caffarella, 1999, p. 293).

Glaser suggests that discovery sequences tend to be inductive and involve "errorful learning," and so is therefore more time-consuming than directed learning (as cited in Marakas, 1995, p. 74). Such sites should encourage resiliency from mistakes and the embedding of learning value in mistake-making. There's a value in scaffolding broad structure options. Learning sequences may not be linear, step-bystep progressions but more recursive, multi-modal, and multi-path options. Self-regulated learners still choose their own paths but with some machine and / or human "weak" advisement. Figure 3 addresses some sequencing concepts.

Communications, collaborations and communities. Discovery spaces need to design channels for people to create authenticated telepresences; meet others with shared interests, backgrounds, or levels of expertise (Liccardi, et al., n.d., p. 224); create partnerships for shared learning and problem-solving, and to organize themselves into strategic virtual teams. Frequent communications may be encouraged not only for information exchange but to alleviate anxiety "caused by misinformation" and to facilitate interaction (Szulanski, 1996, as cited in Sarker, Sarker, Nicholson \& Joshi, June 2005, p. 205). Backchannel communications may be promoted for student directed and free communications for "relevant, contextual, and instructional" learning purposes (Yardi, 2006, p. 854). 


\section{Learning Sequencing Strategies in Discovery Learning Spaces}

(Hai-Jew, 2008)

Some knowledge domains have clear learning trajectories from easy-to-difficult, simple to complex, fundamental to esoteric; general to specific; specific to general, and so on. Discovery learning sites may use learner behavior/performance tracking, learner testing, and so on to scaffold the instruction and to place it on a certain learning sequence.

Time phases may be used to move learning forward. These may be linked to external time events.

Learning may be sequenced based on the challenges of simple-to-difficult problem solving. Certain problems have pre-requisite knowledge and skills needed to solve the challenges; those may be defined by the discovery site builders. It may be helpful for learners to run up against something they can't solve because this leads to selfdirected learning (Hmelo and Coté, n.d., p. 421).

Focusing on a problem may lead to a gaps analysis where current knowledge is assessed in relation to the problems being faced. This analysis may lead to decisions about what learning is necessary. There's also potential learning value in determining whether goals have been met or not (or whether the problem has been solved or not) (Hmelo and Coté, n.d., p. 422).

Another way of viewing this is through the task-discovery relationship: "Gagné provides us with a hierarchy of problem contexts that incorporates the role of discovery as a function of task complexity. An analysis of his hierarchy reveals different functions of discovery for different varieties of problem-solving scenarios. His conceptualization is in keeping with Mechner's position on the task-discovery relationship" (Marakas, 1995, p. 75).

There may also be suggested sequences of activities such as between individual work and group work, asynchronous and synchronous interactivity, and interactive modalities (text, voice, image, and other). "It is not self-evident that learners know how to collaborate constructively. Several studies have shown that collaboration without instruction or support on how to collaborate does not lead automatically to effective knowledge construction (Webb \& Farivar, 1994; Ross \& Cousins, 1995; Mercer, 1996; Chan, 2001)" (Saab, Van Joolingen and Van Hout-Wolters, 2006, pp. 73 - 74).

There may be mixed methods sequencing - the ordering of various learning activities (from brainstorming to reflection), and any range of other complex methods

Mixed methods depending on the learning objectives. Generally, this complexity would suggest live human interaction instead of a machine-determined programmed sequence. Part of this sequencing may also involve the choice of particular online tools.

Figure 3. Learning Sequencing Strategies in Discovery Learning Spaces

These online communities may have learning or knowledge-creation as goals. Such groupings need to be flexible enough to be temporal but persistent enough to last over time. These must also be both inclusive and exclusivist depending on group task and learning needs. Working in groups enhances learning in various ways: "synergy, ability to consider more information, objective evaluation, cognitive 
stimulation, contribution of different understanding and exposure to alternative points of view, that can enhance learning (Benbunan-Fich \& Hiltz, 1999; Hiltz, 1994). Group members can monitor individual thinking and group structure provides social support and encouragement for individual effort...Moreover, working with peers tends to reduce anxiety as learners share solutions to complex tasks, increasing satisfaction with the process and results" (Gerosa, et al., n.d., p. 160). There may be tensions between focusing on high-quality collaborative outcomes "at the cost of neglecting group members with less knowledge" (Ertl, Kopp \& Mandl, n.d., p. 146).

Knowledge management system. An effective discovery learning space should include knowledge management system functionalities-for the application, the generation, the distribution, and storage of knowledge (Yordanova, 2007, p. IV.25-3). Such spaces may help participants "amplify, transform, and extend their work to new or additional outcomes" (Dimitracopoulou, n.d., p. 122). This area should involve digital artifacts, optimally with metadata handling and variable sequencing. Online databases, ontologies, taxonomies, and collections may serve accessible contents and experiences into an information commons. Information needs to be updated constantly, given the fast pace of information depreciation and obsolescence. Figure 4 shows how different discovery learning spaces may meet different needs based on design.

\section{Building up Self Learners}

Self learners have particular discovery learning needs. They need to be self-aware and aware of the environment or learning context. They must employ self-appropriate learning methods. They must adjust their learning activities based on the feedback they get. They must set criteria for their own learning and be able to accurately measure their performance. Wang and $\mathrm{Li}$ assert that self-evaluation is at the core of autonomic learning because it affects the learner ability to "determine and assess tasks, to set goals, and to expect results, but also affects learner's self-supervising and self-reinforcing based on the results of learning (2007, p. 260). Self-regulated learning assumes active learners who "can potentially monitor, control, and regulate certain aspects of their own cognition, motivation, and behavior as well as some features of their environments; that some goal, criterion or standard is used against which to assess learning progress, and that "self-regulatory activities are mediators between personal and contextual characteristics and actual achievement or performance" (Pintrich, 2004, pp. 387 - 388). "The four component skills of the independent learning model are (1) self selection, (2) self-determination, (3) selfmodification, and (4) self-checking" (Chen, Kao, Yu \& Sheu, 2004, n.p.).

Independent learners create an ad hoc learning environment in various life situations; yet, they are also fully capable of using the resources of designed discovery learning environments. Independent learners need information that enhances their own meta-cognition and decision-making. It's critical that selfdriven learners not experience burn-out but maintain the desire to continue learning, which means that they need to learn to pace themselves effectively. They need supports in a site that will not hinder their independence, choice-making, and self-determinism (Wolters \& Pintrich, 1998, p. 29).

The phases of self-regulated learning. Self-regulated learning involves four reflexive (and potentially synchronous) phases in the classroom. Phase 1 involves planning and goal setting as well as activation of perceptions and knowledge of the task and context and the self in relation to the task. Phase 2 concerns various monitoring processes that represent metacognitive awareness of different aspects of the self and task or context. Phase 3 involves efforts to control and regulate different aspects of the self or task and context. Finally, Phase 4 represents various kinds of reactions and reflections on the self and the task or context (Pintrich, 2004, p. 389).

To succeed, learners need to maintain their own motivation and mental - emotional states over time. Self-efficacy affects the breadth of learning strategy use and learner performance as contrasted to task value which was not a significant predictor of actual performance (Wolters \& Pintrich, 1998, p. 44). This would suggest that learner confidence-building measures and the encouragement of internal loci of control may be an important aspect of building discovery learning spaces, especially given self-learner identity formation issues in the learning (Turner, 2006, p. 295). "Self-enthusiasm" drives autonomous learning (Lapidot, 2002, p. 198), so no part of the discovery learning site should diminish that. 
A Continuum of Discovery Learning Spaces Online from Self-Regulated Learning to Learning Communities

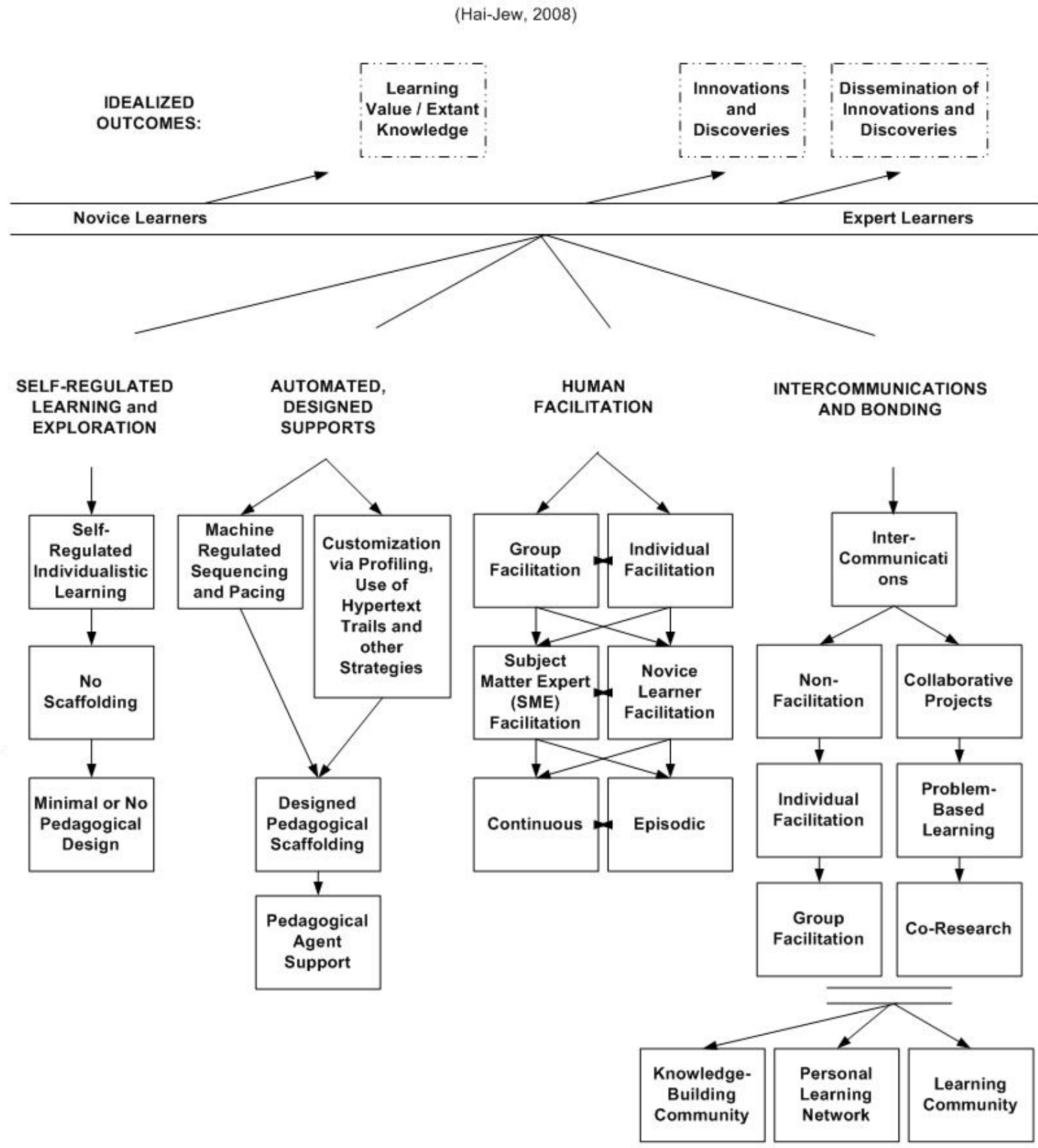

Figure 4. A Continuum of Discovery Learning Spaces Online from Self-Regulated Learning to Learning Communities

Learner ability to structure the space. Self learners tend to attempt to structure their own learning environments to facilitate the goal-setting and task completion" (Zimmerman, 1998, as cited in Pintrich, 2004, p. 399). Goal-setting that focuses on personal mastery may lower competition (and encourage collaboration) with other co-learners as compared to a goal "focused on relative ability and besting others" (Pintrich, 1999, p. 109). In virtual spaces, there should be plenty of levers to adjust a digital, virtual and personalized learning space. One writer has observed situational variance in terms of how self-regulated learners apply various self-regulatory strategies (Pintrich, 1999, p. 111), which could suggest a contextual sensitivity that discovery learning space designers need to focus on. Self regulation 
is a dynamic process (Turner, 2006, p. 293) that is responsive to environmental factors.

Encouraging strategic help-seeking behaviors. A critical part of learning involves help-seeking behaviors. In a discovery learning environment, this may mean accessing relevant resources, reaching out to colearners, contacting experts in the field, or formulating strategic learning relationships in people's own situations. Researchers have noted: "It appears that good students and good self-regulators know when, why, and from whom to seek help" (Karabenick \& Sharma, 1994; Newman, 1998; Ryan \& Pintrich, 1997, as cited in Pintrich, 2004, p. 398).

Maintaining learner engagement. A constant state of challenge and support may offer learners a formula for engagement. Also, discovery sites need to balance the cognitive loads of those in the learning space. Discovery-based multimedia environments' complexity needs to be managed to avoid heavy cognitive loads for learners (Sweller 1999; Paas, Renkl \& Sweller 2003, as cited in Moreno, 2004, p. 100). This is particularly important in the case of novice learners, who lack proper schemas to integrate the new information with their prior knowledge (Tuovinen \& Sweller 1999, as cited in Moreno, 2004, p. 100).

Motivational interference and inhibition processes may affect "memory, cognition, intelligence, reasoning, and self-regulated learning" (Pintrich, 1999, p. 105). Self learners need to develop a strong resistance to interference and attractive activities (Fries \& Dietz, 2007, pp. 93 - 94). Highly motivated learners tend to be less distractible and "not only learned longer and used better strategies but also were more concentrated than and not as easily distractible as less motivated learners" (Fries \& Dietz, 2007, pp. 95 96).

Self discovery learners often demonstrate creativity in their learning. Creativity may suggest sufficient mastery of the domain knowledge in order to add new insights to that body of knowledge. They need to break free of dogma for actual discovery (Marcum, Mar. 2001, p. 103). New content must meet the standards for informational vetting and processes of structured inquiry-before it is accepted for archival and distribution. The eventual exit of self-regulated learners from a discovery space should result in greater applied skills to learning independently in the larger environment.

Learners bring with them a "self-system" related to particular domain knowledge; this self-system consists of stable internal structures involving content-based knowledge of the particular sphere of learning; socio-cultural beliefs about the field; beliefs of the self in the learning domain; "affective schemata", and habitual behavioral patterns related to situations involving the learning subject matter. This self-system may shape each unique learner's approach to a discovery learning space and subject matter domain. Metacognition, combining self-awareness and reflective activity, may be a mitigating factor to help learners handle their self-systems and their affect (Malmivuori, 2006, p. 153).

High-end learning for experts. The needs of novice learners will likely differ from those of subject matter experts (SME). And yet, SMEs play an important role in a Zone of Proximal Development (Vygotsky, 1978) because it is in the interactions between the experts and the novices that there's learning transfer in both directions. SMEs may already have quite a bit of firsthand experience and knowledge in the field already; however, they may be interested in filling gaps in knowledge, seeking new research threads, sharing their ideas, engaging in reinforcement learning, or other motivations. In higher-level learning, expert intervention is necessary at some points of the learning cycle. Some questions may not be resolvable by the learners themselves due to the lack of knowledge or a lack of time (Kam, et al., 2005, p. 538).

\section{The Social Aspects of Self-Learning}

Independent learning does not mean learning alone (Brockett, 1994, as cited in Merriam \& Caffarella, 1999, p. 34). Interactive activities may enhance the respective learners' understandings of learning materials. Such activities may include role plays, interactive analytical discussions, simulations, and case studies.

The setting up of learning community norms, member or non-member facilitation, communications affordances (technology-enhanced capabilities for inter-communications), and other structural elements may be created to support intercommunications, learner bonding, and interdependent co-study. Encouraging communications among co-learners in a discovery learning space may enhance colearning. Bakhtin's concept of dialogicality, a social theory of learning, asserts that "learning is the 
reconciliation of multiple perspectives, including that of the lecturer, the authors of educational resources like textbooks and class handouts (e.g. lecture slides), the learner himself, and other students in the group. Small groups with shared learning and interest in an organization, named as communities of practice, have been recognized as crucial to the exchange and interpretation of information" (Kam, et al., 2005, p. 531). During discourse, learners may externalize their reasoning via language, which may make them aware of deficits in their thoughts. This sharing may help them hone their strategies. "Exploratory talk is a kind of discussion where learners talk through their problems and investigate ideas together" (Saab, Van Joolingen \& Van Hout-Wolters, 2007, p. 74).

Garrison's (1991) interaction analysis model for analyzing online discourse explored knowledge coconstruction. This model involved five phases: "sharing / comparing, dissonance, negotiation, coconstruction, testing and application, which paralleled and built on a conceptualization of critical thinking as a five-stage sequential process: problem identification, problem definition, problem exploration, problem applicability and problem integration" (Law, n.d., p. 374). Some would argue that information evolves to knowledge through dialogues with others. Knowledge building communities are envisioned as "engines for the creation and dissemination of knowledge" (Hoadley \& Kilner, n.d., pp. 32 - 33). Various researchers have offered different strategies to enhance group learning. One is in the field of cooperative note-taking, where students may have augmented annotation with the provision of instructor slides in the background of the synchronous note-taking system or to offer "skeletal lecture notes" for learners to develop with details (Kam, et al., 2005).

Adding new knowledge value to the learning domain. The value-adding to a discovery learning space may not only come from the individual and group experiences of learning but from the rich innovations and new knowledge creation. Without new discoveries, discovery learning spaces may fast become obsolete or irrelevant. There may be absolute novel discovery through inductive efforts (Marakas, 1995, p. 77). Such spaces will likely-based on a nexus of the domain field's professional standards and the contributions of the participants - set a standard for information vetting and discovery. Virtual discovery spaces may archive and showcase various works to the larger learning community or even the WWW publics, through digital artifacts.

For discovery learning spaces to thrive into the future, these will require regular updates to the knowledge bases, the site, and the community. There has to be continuing evolving value for those who participate. Many who traverse the WWW spaces tend to flit, and their transience may militate against any sort of loyalty (Goggins, Laffey \& Tsai, Nov. 2007, p. 209). This places a high and difficult standard of relevance on discovery learning sites.

\section{Future Trends}

Independent learning has moved well beyond the WWW to the mobile learning realm and ambient intelligent spaces. Some researchers who scaffolded independent learning in mobile-learning in natural spaces observed: "Independent learning can assist students in acquiring the knowledge, abilities, skills, values and motivation that enable them to analyze learning situations and develop appropriate strategies for action" (Chen, Kao, Yu \& Sheu, 2004, n.p.).

Developers have strived to build intelligent computer-aided instruction (ICAI) or "educational systems that generate their pedagogical abilities automatically given only a base of domain knowledge" (Rickel, Jan. / Feb. 1989, p. 40). There have been recent pushes to somehow create a persistence of learner identity through multiple discovery learning spaces, with their performance and training records intact, authenticated and editable. There are endeavors to support interoperability between discovery learning systems (Wiesman \& Roos, 2004, n.p.). However, the technological complexity of this endeavor should not be under-estimated.

\section{Conclusion}

There are plenty of opportunities for research in this area of discovery learning spaces online. Researchers may probe what sorts of discovery learning spaces are effective in particular knowledge domains. They may explore what digital supports are useful for particular levels or types of learners and how decision supports may be created for them. It may help to probe what learning sequences are most effective, and why; how different learners may have their needs addressed individually; what strategies there are to build discovery learning in culturally sensitive (or "neutral") ways for global 
learners, and how discovery learning spaces may encourage creative knowledge creation and preservation. It may help to see how self discovery learning exists and is effectively deployed in immersive 3D environments, augmented reality, augmented virtuality, and hybrid learning.

The linked slideshow and PDF file with screenshots of the slideshow offer an overview of the paper and a brief section that highlights some self discovery features in various types of sites.

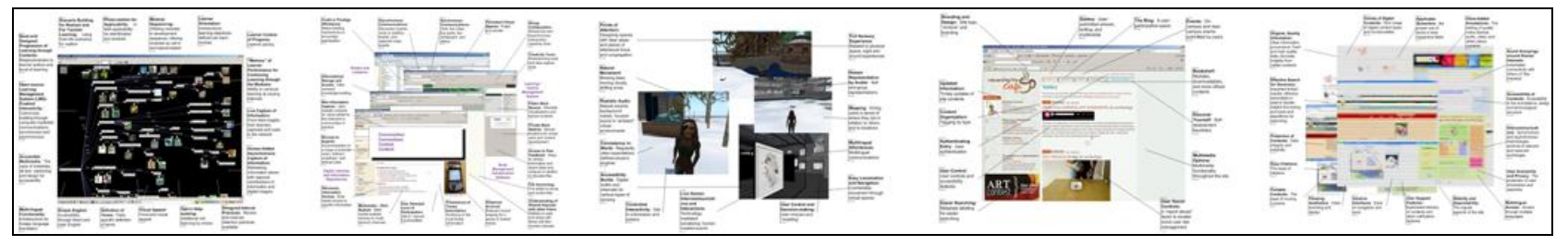

Figure 5. Linked slideshow.

\section{Acknowledgments}

Thanks to R. Max. I am grateful to those who contribute to the self discovery learning spaces and pipelines that enable such rich information sharing and learning.

\section{References}

Annetta, L, Murray, M., Laird, S.G., Bohr, S., \& Park, J. (2008). Investigating student attitudes toward a synchronous, online graduate course in a multi-user virtual learning environment. Journal of Technology and Teacher Education: 16 (1). 5 - 34.

Ardito, C., De Marsico, M., Lanzilotti, R., Levialdi, S., Roselli, T., Rossano, V., \& Tersigni, M. (2004, May). Usability of e-learning tools. Association of Computing Machinery (ACM). $80-84$.

Armstrong, B., \& Perez, R. (2001, Feb.) Controls laboratory program with an accent on discovery learning. IEEE Control Systems Magazine. 14-20.

Bogue, E-L. (1989). Active learning approaches to training: Encouraging the self-taught learner. ACM SIGUCCS XVII. Association of Computing Machinery (ACM). 447 - 452.

Carreras, M. A.M., Skarmeta, A.F.G., \& Graciá, E.M. (2005). Designing collaborative environments and their application in learning. IEEE. n.p.

Chen, Y-S., Kao, T-C., Yu, G-J, \& Sheu, J-P. (2004). A mobile butterfly-watching Learning system for supporting independent learning. Proceedings of the 2nd IEEE International Workshop on Wireless and Mobile Technologies in Education (WMTE'04). n.p.

Clark, R.C. \& Mayer, R. E. (2003). E-Learning and the Science of Instruction. San Francisco: Pfeiffer, A Wiley Imprint.

Dimitracopoulou, A. (n.d.) Designing collaborative learning systems: Current trends \& future research agenda. $115-124$.

Ertl, B., Kopp, B. \& Mandl, H. (n.d.) Effects of an individual's prior knowledge on collaborative knowledge construction and individual learning outcomes in videoconferencing. $145-154$.

Eshet-Alkalai, Y. (2007, Dec.) Humans under bombardment: Performing in a real-time world. InroadsSIGCSE Bulletin: 39 (4). $57-60$.

Fries, S. \& Dietz, F. (2007). Learning in the face of temptation: The case of motivational interference. The Journal of Experimental Education: 76(1).93- 112. 
Gerosa, M. A., Pimentel, M.G., Fuks, H., \& Lucena, C.J.P. (n.d.) No need to read messages right now: Helping mediators to steer educational forums using statistical and visual information. 160 169.

Goggins, S.P., Laffey, J., \& Tsai, I-C. (2007, Nov.). Cooperation and groupness: Community formation in small online collaborative groups. Association for Computing Machinery (ACM). Group'07. 207 216.

Green, J.A., Moos, D.C., Azevedo, R. \& Winters, F.I. (2006). Exploring differences between gifted and grade-level students' use of self-regulatory learning processes with hypermedia. ICLS 2006. 210 216.

Hein, T.L. \& Budny, D.D. (1999). Teaching to students' learning styles: Approaches that work. 29th ASEE / IEEE Frontiers in Education Conference. 12c1-7 to 12c1-14.

Hoadley, C.M. \& Kilner, P.G. (n.d.) Using technology to transform communities of practice into knowledge-building communities. SIGGROUP Bulletin: 25(1). 31 - 40.

Hmelo, C.E. \& Coté, N.C. (n.d.) The development of self-directed learning strategies in problem-based learning. $421-426$.

Junglas, I.A., Johnson, N.A., Steel, D.J., Abraham, D.C. \& Loughlin, P.M. (2007, Nov.) Identity formation, learning styles and trust in virtual worlds. The DATABASE for Advances in Information Systems: 38(4). $90-96$.

Kam, M., Wang, J., Iles, A., Tse, E., Chiu, J., Glaser, D., Tarshish, O. \& Canny, J. (2005). Livenotes: A system for cooperative and augmented note-taking in lectures. CHI: 2005: PAPERS: Educational \& Help Systems. Association of Computing Machinery (ACM). 531 - 540.

Lapidot, T. (2002). Self-assessment as a powerful learning experience. ITICSE '02. 198.

Law, N. (n.d.) Assessing learning outcomes in CSCL settings. $373-377$.

Leathwood, C. (2006). Gender, equity and the discourse of the independent learner in higher education. Higher Education: No. 52. 611-633.

Liccardi, I., Ounnas, A., Pau, R., Massey, E., Kinnunen, P., Lewthwaite, S., Midy, M-A. \& Sarkar, C. (n.d.) The role of social networks in students' learning experiences. $224-227$.

Luckin, R. (2002). Peer to peer convergence: Designing a pedagogical framework for personal learning networks. Proceedings of the International Conference on Computers in Education (ICCE '02). n.p.

Malmivuori, M.L. (2006). Affect and self-regulation. Educational Studies in Mathematics: (63). 149 164.

Marakas, G.M. (1995). The discovery-learning DSS: Allowing for discovery in the decision process. IEEE. $72-81$.

Marcum, J.W. (2001, Mar.) From information center to discovery system: Next step for libraries? The Journal of Academic Librarianship: 27(2). 97 - 106.

McCormack, J. (2007). Artificial ecosystems for creative discovery. GECCO '07. Association of Computing Machinery (ACM). $301-307$.

Merriam, S.B., \& Caffarella, R.S. (1999). Learning in Adulthood: A Comprehensive Guide. 2nd Ed. San Francisco: Jossey Bass Publishers. 36, 289, 293 and 296.

Moore, M. G. (1973, Dec.) Toward a theory of independent learning and teaching. The Journal of Higher Education: 44(9). $661-679$. 
Moreno, R. (2004). Deceasing cognitive load for novice students: Effects of explanatory versus corrective feedback in discovery-based multimedia. Instructional Science: Vol. 32. Kluwer Academic Publishers. $99-113$.

Mullen, P.A. (2007). Use of self-regulating learning strategies by students in the second and third trimesters in an accelerated second-degree baccalaureate nursing program. Journal of Nursing Education: 46(9). $406-412$.

Niemivirta, M. (2006). Assessing motivation and self-regulation in learning within a predictive design: Incorporating systematic elements of change. Educational Psychology Review: 18. $255-259$.

Pata, K., Sarapuu, T., \& Archee, R. (n.d.) Collaborative scaffolding in synchronous environment: Congruity and antagonism of tutor / student facilitation acts. $484-493$.

Pintrich, P.R. (2004). A conceptual framework for assessing motivation and self-regulated learning in college students. Educational Psychology Review: 16 (4). 385 - 407.

Pintrich, P.R. (1999). Understanding interference and inhibition processes from a motivational and selfregulated learning perspective: Comments on Dempster and Corkill. Educational Psychology Review: 11(2). 105 - 115.

Qureshi, S., \& Fayard, A-L. (2008). Virtual teams and development: A language games perspective. Proceedings of the 41st Hawaii International Conference on System Sciences. $1-10$.

Ramalingam, V., LaBelle, D. and Wiedenbeck, S. (2004). Self-efficacy and mental models in learning to program. Association of Computing Machinery (ACM). 171- 175.

Rickel, J.W. (1989, Jan. - Feb.) Intelligent computer-aided instruction: A survey organized around system components. IEEE Transactions on Systems, Man, and Cybernetics: 19(1). 40 - 57.

Saab, N., van Joolingen, W.R. \& van Hout-Wolters, B.H.A.M. (2007). Supporting communication in a collaborative discovery learning environment: The effect of instruction. Instructional Science: 35. 73- 98.

Sarker, S., Sarker, S., Nicholson, D.B. \& Joshi, K.D. (2005, June). Knowledge transfer in virtual systems development teams: An exploratory study of four key enablers. IEEE Transactions on Professional Communication: 48(2). IEEE. $201-218$.

Schloemer, P. and Brenan, K. (2006, Nov. - Dec.) From students to learners: Developing self-regulated learning. Journal of Education for Business: No. 2. 81- 87.

Shafrir, U. and Etkind, M. (2006). E-learning for depth in the semantic web. British Journal of Educational Technology: 37(3). $425-444$.

Stary, C. \& Totter, A. (n.d.) On learner control in e-learning. Trust and Control in Complex SocioTechnical Systems. $41-48$.

Turner, J.C. (2006). Measuring self-regulation: A focus on activity. Educational Psychology Review: 18. $293-296$.

Wang, J. \& Li, F-Z. (2007). Autonomic learning model and algorithm based on DFL. 2007 IEEE International Conference on Granular Computing. IEEE. 259 - 264.

Wiesman, F. \& Roos, N. (2004). Domain independent learning of ontology mappings. AAMAS'04. Association of Computing Machinery (ACM). n.p.

Wolters, C.A. \& Pintrich, P.R. (1998). Contextual differences in student motivation and self-regulated learning in mathematics, English, and social studies classrooms. Instructional Science: 26. 27 - 47.

Wu, S., Lin, C.S., \& Lin, T-C. (2006). Exploring knowledge sharing in virtual teams: A social exchange theory perspective. Proceedings of the 39th Hawaii International Conference on System Sciences. IEEE. 1 - 10. 
Yardi, S. (2006). The role of the backchannel in collaborative learning environments. ICL2006. $852-$ 858.

Yordanova, K. (2007). Integration of knowledge management and e-learning-common features. International Conference on Computer Systems and Technologies-CompSys Tech '07. Association for Computing Machinery (ACM). IV.25-1 to IV.25-6.

Zumbach, J., Schönemann, J., \& Reimann, P. (n.d.) Analyzing and supporting collaboration in cooperative computer-mediated communication. $758-767$.

Manuscript received 15 Jun 2008; revision received 4 Dec 2008.

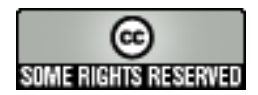

This work is licensed under a

Creative Commons Attribution-NonCommercial-ShareAlike 2.5 License 